\title{
FARNESOL IN COMBINATION WITH $N$-ACETYLCYSTEINE AGAINST STAPHYLOCOCCUS EPIDERMIDIS PLANKTONIC AND BIOFILM CELLS
}

\author{
Fernanda Gomes ${ }^{1}$, Bruna Leite ${ }^{1,2}$, Pilar Teixeira $^{1}$, Joana Azeredo $^{1}$, Rosário Oliveira $^{1^{*}}$
}

${ }^{1}$ IBB-Institute for Biotechnology and Bioengineering, Centre of Biological Engineering, University of Minho, Campus de Gualtar, 4710-057, Braga, Portugal; ${ }^{2}$ Departamento de Biotecnologia, Universidade Federal de São Carlos, São Carlos, SP, Brasil.

Submitted: August 30, 2010; Approved: August 30, 2011.

\begin{abstract}
Staphylococcus epidermidis is the most frequent cause of nosocomial sepsis and catheter-related infections, in which biofilm formation is considered to be the main virulence mechanism. In biofilm environment, microbes exhibit enhanced resistance to antimicrobial agents. This fact boosted the search of possible alternatives to antibiotics. Farnesol and $N$-acetylcysteine (NAC) are non-antibiotic drugs that have demonstrated antibacterial properties. In this study, the effect of farnesol and NAC isolated or in combination (farnesol+NAC) was evaluated. NAC at $10 \times$ MIC caused a total cell death in planktonic cells. On the other hand, $S$. epidermidis biofilms exhibited $4 \log$ reduction in viable cell number after a $24 \mathrm{~h}$ treatment with NAC at the former concentration. Our results demonstrated that there was a higher CFU log reduction of $S$. epidermidis planktonic cells when farnesol was combined with NAC at $1 \times$ MIC relatively to each agent alone. However, these results were not relevant because NAC alone at $10 \times$ MIC was always the condition which gave the best results, having a very high killing effect on planktonic cells and a significant bactericidal effect on biofilm cells. This study demonstrated that no synergy was observed between farnesol and NAC. However, the pronounced antibacterial effect of NAC against S. epidermidis, on both lifestyles, indicates the use of NAC as a potential therapeutic agent in alternative to antibiotics.
\end{abstract}

Key words: Nosocomial infection; biofilm; Staphylococci; farnesol; $N$ - acetylcysteine.

\section{INTRODUCTION}

Staphylococcus epidermidis lives naturally on the skin and mucous membrane as a commensal of the human skin flora (9) and was primarely considered a natural human inhabitant bacterium with a low pathogenic potential (22). However, in recent decades, this bacterium was identified as a common cause of numerous infections on indwelling medical devices (22) and actually $S$. epidermidis is among the most leading causes of nosocomial infections (16). These bacteria form biofilms on implanted medical devices such as central venous catheters (CVCs), urinary catheters, prosthetic heart valves, orthopedic devices, contact lenses, etc, and cause persistent infections (21) and diseases such as septicemia and endocarditis (3). The biofilm-forming ability of Staphylococcus epidermidis has been considered to be its main virulence mechanism $(5,20)$ by which this organism is able to persist in infections/diseases (11). Many implant infections sometimes

*Corresponding Author. Mailing address: IBB-Institute for Biotechnology and Bioengineering, Centre of Biological Engineering, University of Minho, Campus de Gualtar, 4710-057, Braga, Portugal.; Tel: +351 253604409 Fax: +351253-678986.; E-mail: roliveira@ deb.uminho.pt 
requires the implant removal, causing considerable suffering for the patient, with pain and disability and even increased mortality $(8,9)$. Moreover, the long-term systemic antibiotics, surgical debridement, and prolonged hospitalization, greatly increase the costs associated with implant replacement surgery.

The biofilm formation ability is a major clinical problem, mainly due to the intrinsic tolerance/resistance of biofilm cells to antibiotics (5). Antibiotic combination represents a therapeutic option in the treatment of $S$. epidermidis infections (14). However, increasing multiple resistance to antibiotics has made the development of new treatment options for serious infections a matter of urgent concern. In recent years, much research has been devoted to investigating possible alternatives to antibiotics, studying their mode of action and synergistic effects with other antimicrobial compounds. Farnesol is a sesquiterpene alcohol that has demonstrated to inhibit the growth of some microorganisms, such as Staphylococcus aureus and Streptococcus mutans, evidencing its potential use as antimicrobial agent $(6,11)$. The mechanism of action of this sesquiterpenoid probably involves cell membrane damages (6, $11,13)$. $N$-acetylcysteine is another non-antibiotic drug that has antibacterial properties (17). NAC is one of the smallest drug molecules in use and it is generally used in the medical treatment of chronic bronchitis, cancer and paracetamol intoxication (15). The prevention of biofilm formation and adherence to biomaterials devices is another possible role of NAC (17).

Considering the results previously obtained with these compounds, the purpose of this work was to investigate the possible synergistic effect of farnesol with $N$-acetylcysteine against $S$. epidermidis planktonic and biofilm cells.

\section{MATERIALS AND METHODS}

\section{Bacterial strains and culture conditions}

Two clinical isolates of $S$. epidermidis, known for their ability to form biofilms, were used in this work: strain 1457 (isolated from an infected central venous catheter) and strain 9142, a known producer of the polysaccharide intracellular adhesin (PIA). All strains were gently provided by Dr. G. B. Pier, Channing Laboratory, Department of Medicine, Brigham and Women's Hospital, Harvard Medical School, Boston. Both strains were grown for $18 \pm 2 \mathrm{~h}$, at $37^{\circ} \mathrm{C}$ and $120 \mathrm{rpm}$ in $30 \mathrm{~mL}$ of Tryptic Soy Broth (TSB) (Merck, Darmstadt, Germany). Then the cells were centrifuged $\left(9500 \times \mathrm{g}, 5 \mathrm{~min}, 4^{\circ} \mathrm{C}\right)$, washed twice with a saline solution $[0.9 \% \mathrm{NaCl}$ (Merck, Darmstadt, Germany) in distilled water] and sonicated (Ultrasonic Processor, Cole-Parmer Illinois, USA) (22\% amplitude, 10s). The cellular suspensions were adjusted to a final concentration of approximately $1 \times 10^{9}$ cells $\mathrm{mL}^{-1}$, determined by optical density at $640 \mathrm{~nm}$, prior to be used in the subsequent assays.

\section{Planktonic assays}

Viability assays were performed in $100 \mathrm{~mL}$ Erlenmeyers containing a $S$. epidermidis cell suspension $\left(\sim 2 \times 10^{8}\right.$ cells $\mathrm{mL}^{-}$ ${ }^{1}$ ) in the presence of farnesol $(300 \mu \mathrm{M})$ (Sigma, St Louis, USA), NAC $\left(\mathrm{NAC} 1 \times \mathrm{MIC}=4 \mathrm{mg} \mathrm{mL}^{-1}\right.$ and $10 \times \mathrm{MIC}=40$ $\mathrm{mg} \mathrm{mL} \mathrm{m}^{-1}$ ) (Sigma, St Louis, USA) and farnesol-NAC. It should be noted that $300 \mu \mathrm{M}$ farnesol was previously shown to be highly effective against planktonic cells of $S$. epidermidis (7). The suspensions were incubated for 24 hours, at $37^{\circ} \mathrm{C}$ and at $130 \mathrm{rpm}$. Afterwards, cellular viability was assessed by colony forming units (CFU), while cell activity was determined by the XTT (\{2,3-bis(2-methoxy-4-nitro-5-sulfophenyl)-5[(phenylamino)carbonyl]-2H-tetrazolium hydroxide $\})$ (Sigma, St Louis, USA) reduction assay (12).

CFU enumeration: CFU were obtained as follows: 1000 $\mu \mathrm{L}$ of each cellular suspension after being washed with $0.9 \%$ $\mathrm{NaCl}$, were resuspended in $0.9 \% \mathrm{NaCl}$, followed by $20 \mathrm{~s}$ of sonication at $22 \mathrm{~W}$ to homogenize the suspension. This procedure disrupted the cell clumps without impairing cell viability (4). Viable cells were determined by performing 10fold serial dilutions in saline solution and plating in TSA (Merck, Darmstadt, Germany). Colonies were counted after 24 
$\mathrm{h}$ incubation at $37^{\circ} \mathrm{C}$.

XTT assay: For XTT assay, aliquots of $200 \mu \mathrm{L}$ of each cell suspension were collected. The cells were washed with $0.9 \% \mathrm{NaCl}$ by centrifugation for $10 \mathrm{~min}$ at $9500 \times \mathrm{g}$ and $4^{\circ} \mathrm{C}$. The pellet was resuspended in $200 \mu \mathrm{L}$ of $0.9 \% \mathrm{NaCl}$ and dispensed in a well of a microtiter plate. Then, $50 \mu \mathrm{L}$ of a solution containing $200 \mathrm{mg} \mathrm{L}^{-1}$ of XTT and $20 \mathrm{mg} \mathrm{L}^{-1}$ of phenazine methosulphate (PMS) (Sigma, St Louis, USA) were added. The microtiter plates were incubated for $3 \mathrm{~h}$ at $37^{\circ} \mathrm{C}$ in the dark. The absorbance was measured at 490 $\mathrm{nm}$.

Controls included cells not exposed to farnesol or NAC (positive control) and also cells exposed either to farnesol or to NAC alone. All experiments were carried out in triplicate and repeated three times.

\section{Biofilm assays}

Biofilm formation and treatment: Biofilms were formed in 96 well tissue culture plates containing $200 \mu \mathrm{L}$ of S. epidermidis cell suspension $\left(1 \times 10^{6}\right.$ cells $\left.\mathrm{mL}^{-1}\right)(1457$ and 9142 strains $)$ in TSB supplemented with $0.25 \%$ glucose (Merck, Darmstadt, Germany) per well to promote biofilm formation. Plates were incubated for $24 \mathrm{~h}$ at $37^{\circ} \mathrm{C}$ on an orbital shaker (130 rpm). At the end, planktonic cells were removed carefully, and the biofilm was washed twice with $200 \mu \mathrm{L}$ of $0.9 \% \mathrm{NaCl}$. The biofilms were incubated in fresh nutrient medium containing farnesol $(300 \mu \mathrm{M})$, NAC $(1 \times$ MIC and $10 \times$ MIC) and combination of both. XTT, $\mathrm{CFU}$ and crystal violet $(\mathrm{CV})$ assays were performed after 24 hours of exposure to antimicrobial agents (alone and in combination) tested. At time 0 (before exposure to antimicrobial agents) the initial cellular concentration of biofilm $\left(\sim 2 \times 10^{8}\right.$ cells $\left.\mathrm{mL}^{-1}\right)$ was determined.

XTT assay: The quantification of biofilm cellular activity was assessed through the XTT reduction assay. After exposure to farnesol and NAC, biofilms were washed with $0.9 \% \mathrm{NaCl}$. Then, $250 \mu \mathrm{L}$ of a solution containing $200 \mathrm{mg} \mathrm{L}^{-1}$ of XTT and $20 \mathrm{mg} \mathrm{L}^{-1}$ of PMS were added to each well. The microtiter plates were incubated for $3 \mathrm{~h}$ at $37^{\circ} \mathrm{C}$ in the dark. The absorbance was measured at $490 \mathrm{~nm}$.

CFU enumeration: $\mathrm{CFU}$ were obtained as follows: the planktonic cells were removed carefully and the biofilm was washed twice with $200 \mu \mathrm{L}$ of $0.9 \% \mathrm{NaCl}$. The wells were thoroughly scraped and ressuspended in $1 \mathrm{~mL}$ of $0.9 \% \mathrm{NaCl}$, followed by centrifugation for $10 \mathrm{~min}$ at $9500 \times \mathrm{g}$. The pellet was resuspended in $0.9 \% \mathrm{NaCl}$ and washed twice, followed by $20 \mathrm{~s}$ of sonication at $22 \mathrm{~W}$ to homogenize the suspension. Viable cells were determined by performing 10 -fold serial dilutions in saline solution and plating in TSA. Colonies were counted after $24 \mathrm{~h}$ incubation at $37^{\circ} \mathrm{C}$.

Crystal Violet assay: CV was used as indicator of total biofilm biomass. For the measurement of this parameter, biofilms were washed with $250 \mu \mathrm{L}$ of $0.9 \% \mathrm{NaCl}$, then $250 \mu \mathrm{L}$ of methanol (Merck, Darmstadt, Germany) were added and left to act during 15 minutes. Afterwards, methanol was removed and $250 \mu \mathrm{L}$ of crystal violet 1\% (v/v) (Merck, Darmstadt, Germany) were added (5 min). The wells were washed with distilled water and finally, acetic acid $33 \%$ (v/v) (Merck, Darmstadt, Germany) was added. The absorbance was measured at $570 \mathrm{~nm}$.

Controls were cells not exposed to farnesol or NAC (positive control), and cells exposed either to farnesol or NAC alone. All experiments were carried out in triplicate and repeated three times.

\section{Scanning Electron Microscopy (SEM)}

Biofilms were dehydrated by immersion in increasing ethanol (Merck, Darmstadt, Germany) concentration solutions: 70 (10 $\min ), 95(10 \mathrm{~min})$ and $100 \%(20 \mathrm{~min})(\mathrm{v} / \mathrm{v})$, having then been placed in a sealed desiccator. Samples were mounted on aluminium strubs with carbon tape, sputter coated with gold and observed with a Field Emission Gun - Scanning Electron Microscope (FEG/ESEM) - Nova Nano SEM 200 from FEI Company.

Three fields were used for image analysis. All photographs were taken at a magnification of $\times 40000$.

\section{Statistical analysis}

The results from all assays were compared by the one-way analysis of variance by applying the Bonferroni and Tukey multiple comparison tests, using the SPSS (Statistical Package for the Social Sciences Inc, Chicago). All tests were performed with $95 \%$ confidence level. 


\section{RESULTS}

Figure 1 presents the effect of farnesol, NAC and the association farnesol-NAC on Staphylococcus epidermidis planktonic cells. NAC at $1 \times$ MIC concentration is less effective than farnesol at $300 \mu \mathrm{M}(\mathrm{p}<0.05)$ (Fig. 1). The combination of farnesol at $300 \mu \mathrm{M}$ with $\mathrm{NAC}$ at $1 \times \mathrm{MIC}$ caused a higher CFU log reduction when compared to each one

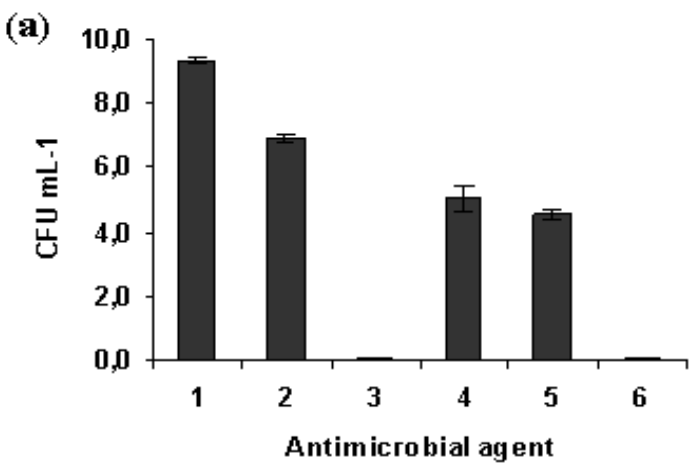

alone $(\mathrm{p}<0.05)$. This combination resulted into an additional $\log$ reduction of 0.5 and 1 for strains 1457 and 9142, respectively $(\mathrm{p}<0.05)$ and relatively to the most effective of both antimicrobial agents tested, ie farnesol at $300 \mu \mathrm{M}$. However, NAC at $10 \times$ MIC was more effective than farnesol alone and farnesol and NAC $1 \times$ MIC. After 24 hours, NAC 10 $\times$ MIC caused 8 log reduction resulting in total cell death (Fig. $1)$.

(b)

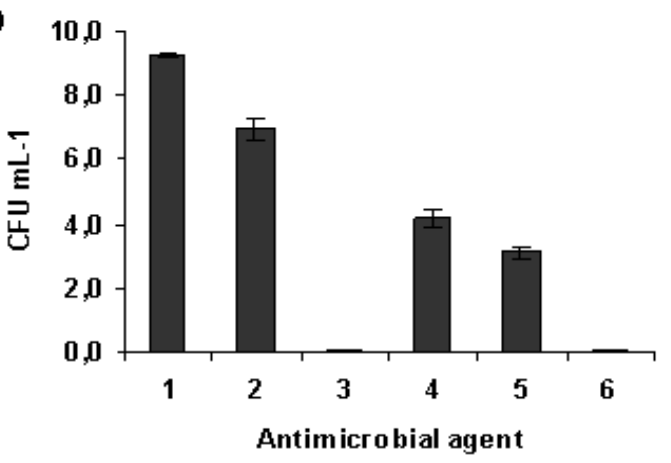

Figure 1. Effect of farnesol and/or NAC on planktonic cells of S. epidermidis 1457 (a) and 9142 (b), after 24 hours of contact with farnesol (300 $\mu \mathrm{M})$, NAC (4 mg mL ${ }^{-1}$ and $40 \mathrm{mg} \mathrm{mL}^{-1}$ ) and farnesol-NAC. Error bars represent standard deviation. Legend: 1- Positive control; $2-\mathrm{NAC} 1 \times$ MIC; 3- NAC $10 \times$ MIC; 4- Farnesol $300 \mu \mathrm{M}$; 5- Farnesol $300 \mu \mathrm{M}+$ NAC $1 \times$ MIC; 6- Farnesol $300 \mu \mathrm{M}+$ NAC $10 \times$ MIC.

Relatively to biofilm cells, although NAC $10 \times$ MIC did not cause total cell death it was the most efficient against $S$. epidermidis biofilm cells causing a reduction of approximately 4 $\log$ (Fig. 2). Conversely to planktonic cells, farnesol and NAC $1 \times$
MIC had a similar effect in biofilms. For strain 1457, NAC $1 \times$ MIC and farnesol worked better together than alone $(\mathrm{p}<0.05)$ (Fig. 2a). There was no synergistic or additional effect when NAC $10 \times$ MIC was combined with farnesol at $300 \mu \mathrm{M}(\mathrm{p}<0.05)$.
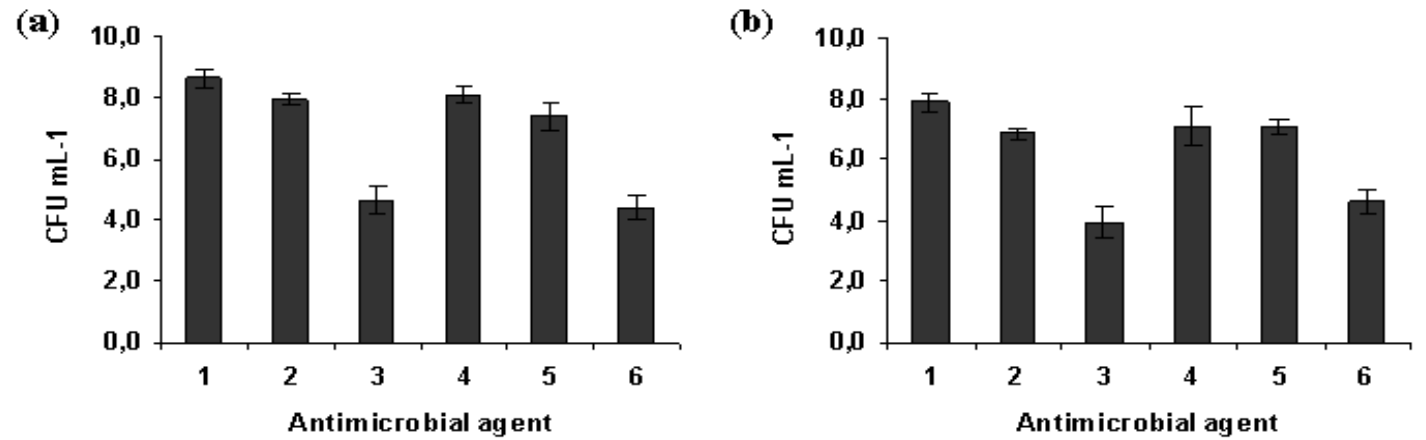

Figure 2. Effect of farnesol and/or NAC on biofilm cells of S. epidermidis 1457 (a) and 9142 (b), after 24 hours of contact with farnesol (300 $\mu \mathrm{M})$, NAC (4 mg mL $\mathrm{md}^{-1}$ an $40 \mathrm{mg} \mathrm{mL}^{-1}$ ) and farnesol-NAC. Error bars represent standard deviation. Legend: 1- Positive control; $2-\mathrm{NAC} 1 \times$ MIC; 3- NAC $10 \times$ MIC; 4- Farnesol $300 \mu$ M; 5- Farnesol $300 \mu \mathrm{M}+$ NAC $1 \times$ MIC; 6- Farnesol $300 \mu \mathrm{M}+$ NAC $10 \times$ MIC. 
The results of the XTT reduction assay, indicative of the metabolic activity of cells within the biofilm and CV staining assay, which allows the quantification of the total biofilm biomass, after a $24 \mathrm{~h}$ treatment with farnesol, NAC, and farnesol+NAC are presented in table 1. These results confirmed the absence of synergy between farnesol and NAC. $\mathrm{NAC}$ at $10 \times \mathrm{MIC}$ was the antimicrobial agent treatment more efficient against both $S$. epidermidis strains tested, causing a significant decrease in the metabolic activity of biofilm cells and total biofilm biomass $(\mathrm{p}<0.05)$.

Table 1. Optical density (absorbance) and confidence interval obtained from XTT and Crystal Violet assays in biofilm cells of $S$. epidermidis after exposure to farnesol, NAC and farnesol/NAC combination.

\begin{tabular}{|c|c|c|c|c|}
\hline \multirow[b]{2}{*}{ Condition } & \multicolumn{2}{|c|}{ S. epidermidis 1457} & \multicolumn{2}{|c|}{ S. epidermidis 9142} \\
\hline & XTT & $\mathbf{C V}$ & XTT & $\mathbf{C V}$ \\
\hline Positive control & $3.124 \pm 0.151$ & $2.735 \pm 0.280$ & $2.314 \pm 0.099$ & $2.807 \pm 0.279$ \\
\hline NAC $1 \times \mathrm{MIC}$ & $1.720 \pm 0.149$ & $2.649 \pm 0.232$ & $1.452 \pm 0.078$ & $2.577 \pm 0.281$ \\
\hline NAC $10 \times \mathrm{MIC}$ & $1.277 \pm 0.173$ & $1.931 \pm 0.117$ & $1.124 \pm 0.156$ & $1.817 \pm 0.204$ \\
\hline Farnesol $300 \mu \mathrm{M}$ & $1.910 \pm 0.185$ & $2.763 \pm 0.250$ & $1.715 \pm 0.097$ & $2.260 \pm 0.379$ \\
\hline Farnesol $300 \mu \mathrm{M}+$ NAC $1 \times$ MIC & $1.928 \pm 0.148$ & $2.707 \pm 0.241$ & $1.498 \pm 0.161$ & $2.132 \pm 0.386$ \\
\hline Farnesol $300 \mu \mathrm{M}+\mathrm{NAC} 10 \times \mathrm{MIC}$ & $1.360 \pm 0.106$ & $1.868 \pm 0.127$ & $1.195 \pm 0.169$ & $1.681 \pm 0.290$ \\
\hline
\end{tabular}

Representative scanning electron microscopy images of 1457 S. epidermidis biofilms after being exposed to farnesol, NAC and farnesol-NAC are presented on figure 3. These images specifically show the effect on the biofilm matrix and biofilm cell viability, and are in agreement with the results presented above. All biofilms treated with NAC revealed a desintegration of the matrix which is more noticeable for NAC at $40 \mathrm{mg} \mathrm{mL}^{-1}$ (10x MIC). Farnesol seems to have also an effect on biofilm matrix but not as pronounced as NAC.
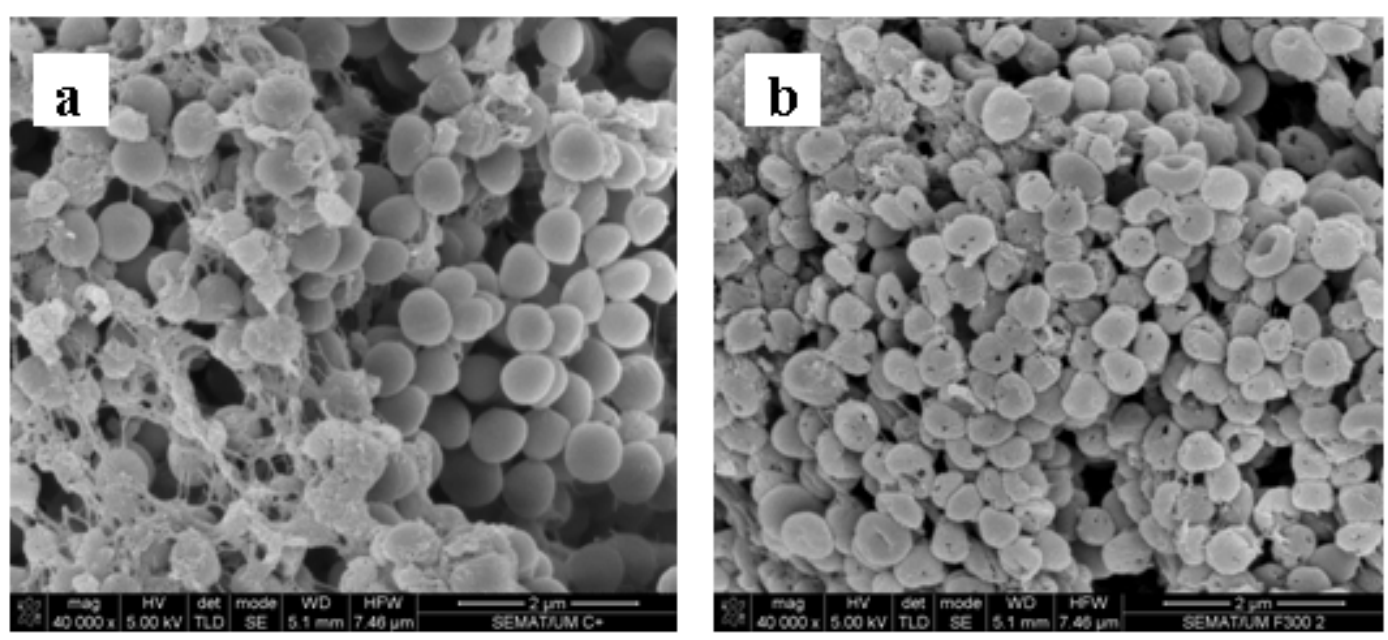

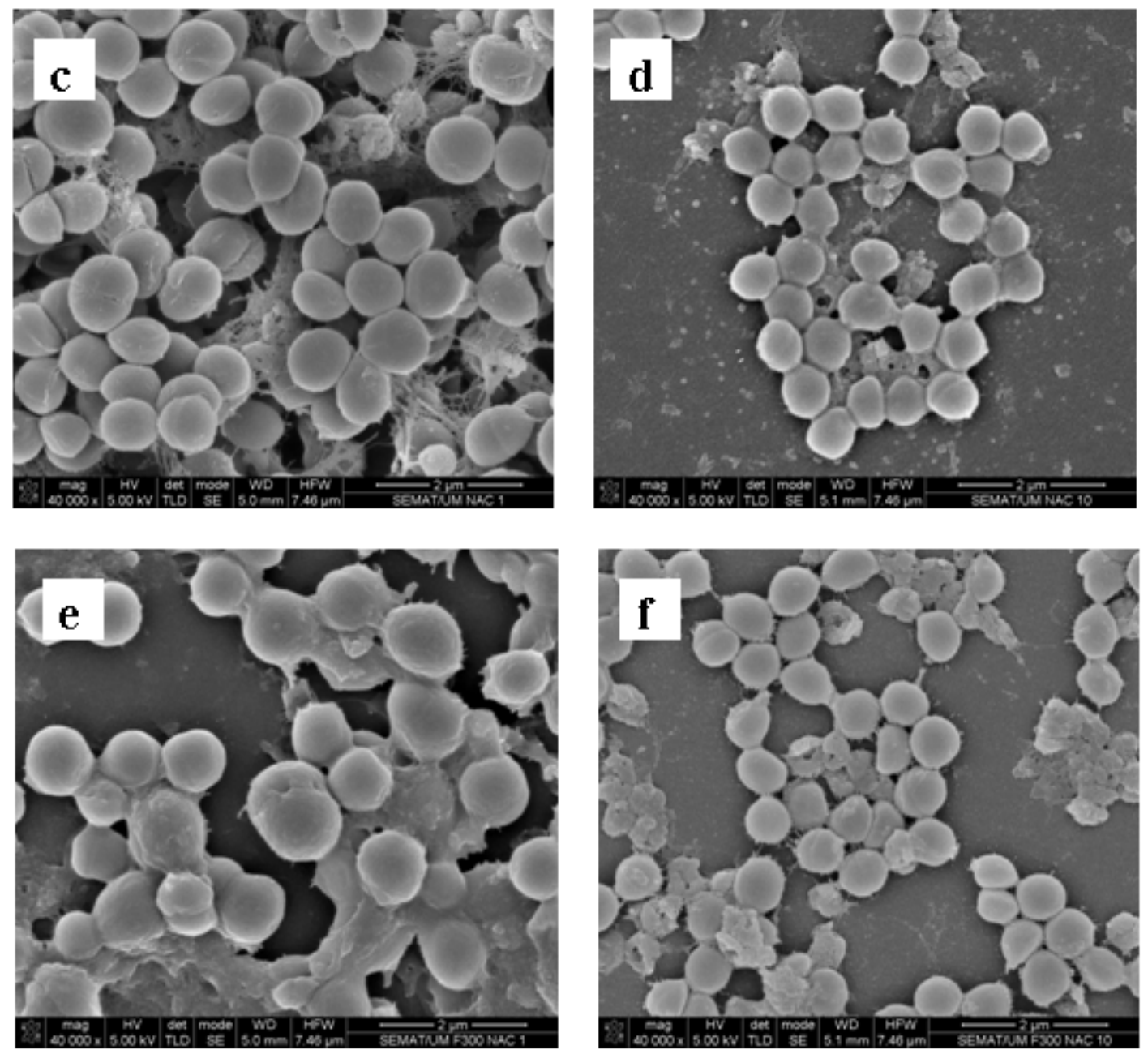

Figure 3. Scanning electron micrographs of 24 h-biofilm of S. epidermidis 1457 after exposure to farnesol, NAC, and the combination of both for 24 h. (a) Positive control; (b) $300 \mu \mathrm{M}$ farnesol; (c) NAC $1 \times$ MIC; (d) NAC $10 \times$ MIC; (e) Farnesol 300 $\mu \mathrm{M}+\mathrm{NAC} 1 \times \mathrm{MIC}$; (f) Farnesol $300 \mu \mathrm{M}+\mathrm{NAC} 10 \times$ MIC. Magnification $\times 40000$.

\section{DISCUSSION}

In this work, the effect of farnesol, NAC and farnesolNAC combination against $S$. epidermidis planktonic and biofilm cells was studied. For that, two good biofilm-forming strains were selected, strains 1457 and 9142 (19). Comparing these two strains, 1457 produces slightly more biofilm than 9142 (19). The biofilm formation ability is due to the formation of PIA homopolymer, which surrounds and connects $S$. epidermidis cells in biofilm form (16). The extracellular matrix is extremely important for intercellular connection during surface colonization (10) and protection against the host immune system and resistance to antibiotics (1). Figure $3 \mathrm{a}$ represents a 48 hours biofilm of $S$. epidermidis 1457 and shows the thickness of biofilm and the presence of a noticeable amount of biofilm matrix.

$\mathrm{N}$-acetylcysteine (NAC), a potent antioxidant that reduces disulphide bonds linking mucin oligomers, has been widely used as a mucolytic agent for inhalation therapy in patients with chronic bronchitis. NAC has been shown not only to 
reduce adhesion but also to detach bacterial cells adhered to surfaces and to inhibit bacterial growth in vitro (15). NAC decreases biofilm formation by a variety of bacteria and reduces the production of extracellular polysaccharide matrix, while promoting the disruption of mature biofilm (2).

On the other hand, the principal interaction of farnesol appears to be with the cytoplasmatic membrane (11). Farnesol is a sesquiterpenoid that already demonstrated synergistic effect with another antimicrobial agent (gentamicin) indicating a potential application as an adjuvant therapeutic agent (11). According to previous studies, where farnesol was tested at concentrations ranging from 30 to $300 \mu \mathrm{M}$, the last concentration demonstrated to have an antimicrobial effect against $S$. epidermidis as well as against other bacteria $(7,11)$.

We hypothesized that the combination of NAC with farnesol could be synergystic in the treatment of S. epidermidis infections as they both act on different components of the biofilm. Our results revealed that additionally to be bactericidal NAC seems also to act against the matrix. In fact, NAC seems to destroy the biofilm matrix resulting in the detachment of cells and thus the biofilm cells become more exposed and susceptible. This high effect against biofilm cells of $S$. epidermidis must be due in part to the small molecular size of NAC (Molecular Weight $=163.19$ ), which easily penetrates into the biofilm. NAC at $1 \times$ MIC in combination with $300 \mu \mathrm{M}$ farnesol resulted in a higher antimicrobial effect against planktonic cells of S. epidermidis 1457 and 9142 than both antimicrobial agents alone. Nevertheless NAC alone at $10 \mathrm{x}$ MIC, similarly to biofilms, showed a very high bactericidal effect. Although its very high effect on planktonic cells promoting $\mathrm{CFU}$ reductions above $8 \mathrm{log}$, it is probably more impressive its bactericidal effect on biofilms, which are always very tolerant to the most common antibiotics (7). However, unlike it was expected it did not work in synergy with farnesol at $300 \mu \mathrm{M}$ against biofilm cells.

Comparatively to planktonic cells, biofilm cells were much more tolerant to the inhibitory effect of farnesol, NAC and farnesol-NAC. As mentioned above, this fact must be due to the protective effect of the matrix. The effect of NAC was concentration dependent. While with NAC at $1 \times \mathrm{MIC}$ an average reduction of $2.5 \log$ was observed, NAC $10 \times$ MIC was enought to kill all planktonic cells. However, for biofilm cells this concentration $(10 \times$ MIC) only promoted an approximatly $4 \log$ reduction in the number of viable cells within the biofilm, while only $1 \log$ was attained with $1 \times$ MIC.

The peak serum concentration of NAC after a $600 \mathrm{mg}$ oral dose was estimated to be $0.465 \mathrm{mg} \mathrm{mL}^{-1}$ (18). The concentrations of NAC tested in our study $(1 \times \mathrm{MIC}$ and $10 \times$ MIC, 4 and $40 \mathrm{mg} \mathrm{mL}^{-1}$ ) are rather higher than those reached in serum when applied by the intravenous or oral route. However, when applied locally it may be possible to obtain concentrations that prevent the formation of biofilms and consequently the adherence of $S$. epidermidis. (17).

In another study, a concentration of $80 \mathrm{mg} \mathrm{mL}^{-1}$ of NAC was tested in vitro based on preliminary data that showed a dose-response relashionship on planktonic bacteria (2). Based in these results it seems to be feasible the use of $40 \mathrm{mg} \mathrm{mL}^{-1}$ in vivo.

In conclusion, $\mathrm{NAC}$ at $40 \mathrm{mg} \mathrm{mL}^{-1}$ was the only of the tested treatments that was bactericidal against $S$. epidermidis cells both in planktonic or in biofilm form. Moreover, although NAC and farnesol have different modes of action, the combination of both has no significant synergistic effect.

\section{ACKNOWLEDGEMENTS}

Fernanda Gomes and Pilar Teixeira fully acknowledge the financial support of Fundação para a Ciência e Tecnologia (FCT) through the grants SFRH/BD/32126/2006 and SFRH/BPD/26803/2006, respectively.

\section{REFERENCES}

1. An, Y.; Friedman, R. (1997). Laboratory methods for studies of bacterial adhesion. J. Microbiol. Methods 30, 141-152. 
2. Aslam, S.; Trautner, B.W.; Ramanathan, V.; Darouiche, R. (2007). Combination of tigecycline and $\mathrm{N}$-acetylcysteine reduces biofilmembedded bacteria on vascular catheters. Antimicrob. Agents Chemother. 51, 1556-1558.

3. Cargill, J.S.; Upton, M. (2009). Low concentration of vancomycin stimulate biofilm formation in some clinical isolates of Staphylococcus epidermidis. J. Clin. Pathol. 62, 1112-1116.

4. Cerca, N.; Martins, S.; Cerca, F.; Jefferson, K.K.; Pier, G.B.; Oliveira, R.; Azeredo, J. (2005a). Comparative assessment of antibiotic susceptibility of coagulase-negative staphylococci in biofilm versus planktonic culture as assessed by bacterial enumeration or rapid XTT colorimetry. J. Antimicrob. Chemother. 56, 331-336.

5. Cerca, N.; Martins, S.; Sillankorva, S.; Jefferson, K.K.; Pier, G.B.; Oliveira, R.; Azeredo, J. (2005b). Effects of growth in the presence of subinhibitory concentrations of dicloxacillin on Staphylococcus epidermidis and Staphylococcus haemolyticus biofilms. Appl. Environ. Microbiol. 71, 8677-8682.

6. Derengowski, L.S.; De-Souza-Silva, C.; Braz, S.V.; Mello-De-Sousa, T.M.; Báo, S.N.; Kyaw, C.M.; Silva-Pereira, I. (2009). Antimicrobial effect of farnesol, a Candida albicans quorum sensing molecule, on Paracoccidioides brasiliensis growth and morphogenesis. Ann. Clin. Microbiol. Antimicrob. 8, 13.

7. Gomes, F.I.A.; Teixeira, P.; Azeredo, J.; Oliveira, R. (2009). Effect of farnesol on planktonic and biofilm cells of Staphylococcus epidermidis. Curr. Microbiol. 59, 118-122.

8. Hajdu, S.; Lassnigg, A.; Graninger, W.; Hirschl, A.M.; Presterl, E. (2009). Effects of vancomycin, daptomycin, fosfomycin, tigecycline, and ceftriaxone on Staphylococcus epidermidis biofilms. J. Orthop. Res. 27, 1361-1365.

9. Hellmark, B.; Unemo, M.; Nilsdotter-Augustinsson, A.; Söderquist, B. (2009). Antibiotic susceptibility among Staphylococcus epidermidis isolated from prosthetic joint infections with special focus on rifampicin and variability of the rpoB gene. Clin. Microbiol. Infect. 15, 238-244.

10. Hussain, M.; Hasting, J.G.M.; White, P.J. (1991). Isolation and composition of the extracellular slime made by coagulase staphylococci in a chemically defined medium. J. Infect. Dis. 163, 534-541.

11. Jabra-Rizk, M.A.; Meiller, T.F.; James, C.E.; Shirtliff, M.E. (2006). Effect of farnesol on Staphylococcus aureus biofilm formation and antimicrobial susceptibility. Antimicrob. Agents Chemother. 50, 1463-
1469.

12. Kuhn, D.M.; Balkis, M.; Chandra, J.; Mukherjee, P.K.; Ghannoum, M.A. (2003). Uses and limitations of the XTT assay in studies of Candida growth and metabolism. J. Clin. Microbiol. 41, 506-508.

13. Kuroda, M.; Nagasaki, S.; Ohta, T. (2007). Sesquiterpene farnesol inhibits recycling of the $\mathrm{C}_{55}$ lipid carrier of the murein monomer precursor contributing to increased susceptibility to $\beta$-lactams in methicillin-resistant Staphylococcus aureus. J. Antimicrob. Chemother. $59,425-432$.

14. Monzón, M.; Oteiza, C.; Leiva, J.; Amorena, B. (2001). Synergy of different antibiotic combinations in biofilms of Staphylococcus epidermidis. J. Antimicrob. Chemother. 48, 793-801.

15. Olofsson, A.; Hermansson, M.; Elwing, H. (2003). $N$-acetyl-L-Cysteine affects growth, extracellular polysaccharide production, and bacterial biofilm formation on solid surfaces. Appl. Environ. Microbiol. 69, 4814 4822.

16. Otto, M. (2009). Staphylococcus epidermidis- the "accidental" pathogen. Microbiology 7, 555-567.

17. Pérez-Giraldo, C.; Rodriguez-Benito, A.; Moran, F.J.; Hurtado, C.; Blanco, M.T.; Gomez-Garcia, A.C. (1997). Influence of $N$-acetylcysteine on the formation of biofilm by Staphylococcus epidermidis. J. Antimicrob. Chemother. 39, 643-646.

18. Rehman, T.; Fought, J.; Solomon, R. (2008). $N$-acetylcysteine effect on serum creatinine and cystatin C levels in CKD Patients. Clin. J. Am. Soc. Nephrol. 3, 1610-1614.

19. Sousa, C.; Teixeira, P.; Oliveira, R. (2009). The role of extracellular polymers on Staphylococcus epidermidis biofilm biomass and metabolic activity. J. Basic Microbiol. 49, 363-370.

20. Vuong, C.; Kocianova, S.; Yao, Y.; Carmody, A.B.; Otto, M. (2004). Increased colonization of indwelling medical devices by quorum-sensing mutants of Staphylococcus epidermidis in vivo. J. Infect. Dis. 2004; 190, 1498-1505.

21. Wang, C.; Li, M.; Dong, D.; Wang, J.; Ren, J.; Otto, M.; Gao, Q. (2007). Role of ClpP in biofilm formation and virulence of Staphylococcus epidermidis. Microbes Infect 9, 1376-1383.

22. Ziebuhr, W.; Hennig, S.; Eckart, M.; Kränzler, H.; Batzilla, C.; Kozitskaya, S. (2006). Nosocomial infections by Staphylococcus epidermidis: how a commensal bacterium turns into a pathogen. Int. J. Antimicrob. Agents 28, 14-20. 